ENSV TEADUSTE AKADEEMIA TOIMETISED. XVI KÖIDE

KEEMIA * GEOLOOGIA. 1967, Nr. 2

ИЗВЕСТИЯ АКАДЕМИИ НАУК ЭСТОНСКОЙ ССР. ТОМ ХVI

Химия * ГЕОЛОГИя. 1967. №2 2

Х. АНДРА, Ю. ХЕИНСАЛУ, Г. ЮРГЕНФЕЛЬДТ

\title{
О ПРИМЕНЕНИИ ПОДЗЕМНОГО ЭЛЕКТРИЧЕСКОГО ПРОФИЛИРОВАНИЯ ДЛЯ ИЗУЧЕНИЯ ЗАКАРСТОВАННЫХ ЗОН ТЕКТОНИЧЕСКИХ НАРУШЕНИИ
}

Среди вопросов, связанных с исследованием геологии эстонского сланцевого месторождения, большое значение имеет изучение широко распространенных здесь закарстованных зон тектонических нарушений. Несмотря на то, что изучением этих зон занимались многие исследователи (Гатальский, 1957; Газизов, 1958, 1962, 1964; Левыкнн, 1962 и др.), все же необходимо дальнейшее уточнение их строения и закономерностей распространения, а также усовершенствование методики исследования. Необходимо определить ширину и характер названных зон на уровне промышленной пачки горючих сланцев и ее непосредственной кровли. Эти данные позволят рациональнее гланировать горные выработки, лучше управлять горным давлением и добиваться более высоких показателей при добыче сланца. Например, от детальности изучения закарстованных зон зависят правильный выбор вида крепи, уровень потерь сланца по геологическим причинам, выбор способа дренажа непосредственной кровли и установ.ение ширины камер при камерной системе разработки.

Для более объективного суждения о применимости подземного электрического профилирования приведем краткую характеристику геологического строения месторождения горючих сланцев.

Коренными породами Эстонского сланцевого бассейна являются известняки и глинистые известняки ордовика, которые падают в южном направлении под углом в среднем $0^{\circ} 15^{\prime}$ и имеют мощность до $150 \mathrm{M}$. Промышленные слои горючих сланцев, мощностью около $3 \mu$, залегают на глубине от $1-2$ м в северной до $50-60 \mu$ в южной части месторождения. Коренные породы покрыты маломощными четвертичными отложениями. Зоны тектонических нарушений имеют обычно ширину от 10 до 300 м и длину от нескольких сотен метров до нескольких километров. Зоны осложнены трещинами и сбросами с амплитудой от 0,1 до нескольких метров. В центральной части зон местами наблюдается поднятие или опускание слоев с амплитудой от 0,5 до $2 \mathrm{~m}$ Породы в зонах нарушений обычно доломитизированы. Карст в этих зонах проявляется в виде мелких пустот и полостей (высота которых редко достигает $1-2 \mathrm{~s}$ ), заполненных обычно глинисто-песчаным материалом; породы кавернозны. В слоях, содержащих органическое вещество, наблюдается изменение пород в результате окислєння и выщелачивания. В этнх местах вместо горючего сланца встречается глина с хорошо сохранившимися конкрециями н прослойками известняка, а вместо известняка, содержащего органическое вещество, - глинистый известняк. Такое изменение пород произошло вдоль трещин северо-восточного простирания.

В 1964-1965 гг. Институт геологии АН ЭССР произвел на эстонском месторожденин горючих сланцев комплексное геолого-геофизическое изучение закарстованных зон тектонических нарушений; были прове- 
дены электрометрические исследования на поверхности шахтных полей и по штрекам шахт. Цель подземных исследований состояла в детальном изучении геоэлектрического и геологического строения зон нарушений на уровне промышленного пласта и в сопоставлении аномалий кажущегося удельного сопротивления $\left(\varrho_{k}\right)$, полученных на поверхности шахтных полей и в горных выработках.

Подземное электрическое профнлирование проводилось с помощь: симметричной установки с $A B=40 \mu, M N=10 м$ и $A B=2 \mu, M N=0,3 м$ при шаге 5 s. Электрическое профилирование производили по одному и тому же етратнграфическому слою, напрнмер по подошве промышленной пачки. По профилям документировались трещинонатость піород, изменения гипсометрии подошвы промпачки и другие признаки, на основе которых устанавливались границы закарстованных участков, что отмечалось условнымн знаками на стенках и в кровле штрека.

Зоны закарстованных нарушений были выявлены с поверхности шахтных полей дипольным профилированием; определение ширины таких зон проводилось по характерным точкам кривых профилирований (Блох, 1962; Вешев, 1965).

По данным вертикальных электрических зондирований составлены геоэлектрическне разрезы зон нарушений. Установлено, что в случае ннтенсивной закарстованности пачки горючего сланца для $\varrho_{k}$ (при 1/2 $A B=100$ м) характерны более низкие значения (рис. 1).

При помощи буровых скважин было установлено, что низкие значення $\varrho_{k}$ обусловлены глинистыми породами, образовавшимися здесь в результате выветривания и выщелачивания горючих сланцев и известняков, содержащих органическое вещество.

Исследования показали, что закарстованные нарушения вызывают аномалии $\varrho_{k}$, минимумы которых соответствуют нанболее закарстованным и трещиноватым участкам. Величина понижения значений $\varrho_{k}$ около сильно закарстованной центральной части нарушений тесно связана с интенсивностью трещиноватости. Например, из рис. 2 видно, что в юговосточной стороне нарушения среднее значение $\varrho_{k}$ меньше, чем в северо-западной, что обусловлено наличием здесь группы обводненных и слабо закарстованных трещин северо-восточного простирания. В случае, когда на плечах закарстованных зон имеется сильно развитая трещиноватость, по $\varrho_{k}$ можно судить о приближении горной выработки к карсту, что всегда можно определить при помощи подземного симметрнчного электрического профилирования. Однако сильная трещиноватость начинается обычно весьма близко - в 5-15 $\mu$ - от карста.

Сравнение геологических и геофизических данных показывает следующее. «Рудный крест» дипольного электрического профилирования, полученный на поверхности земли, и центр аномалий, выявленный при подземном симметричном электрическом профилировании, маркирует центральную часть закарстованного нарушения.

Обычно интенсивность аномалии обоих электрических профилей имеет на соответствующих участках нарушения одинаковый характер. Следовательно, на образование электрической аномалии при надземном профилировании значительное влияние оказывает характер трещиноватости и закарстованности, развитый на уровне промышленного пласта сланцев.

При ведении горных работ важно заблаговременно знать наличне, характер и размеры тектоннческих нарушений в пределах промышленного пласта горючих сланцев и непосредственной его кровли. Такую информацию можно получить в случаях, когда штрек проходит накрест 


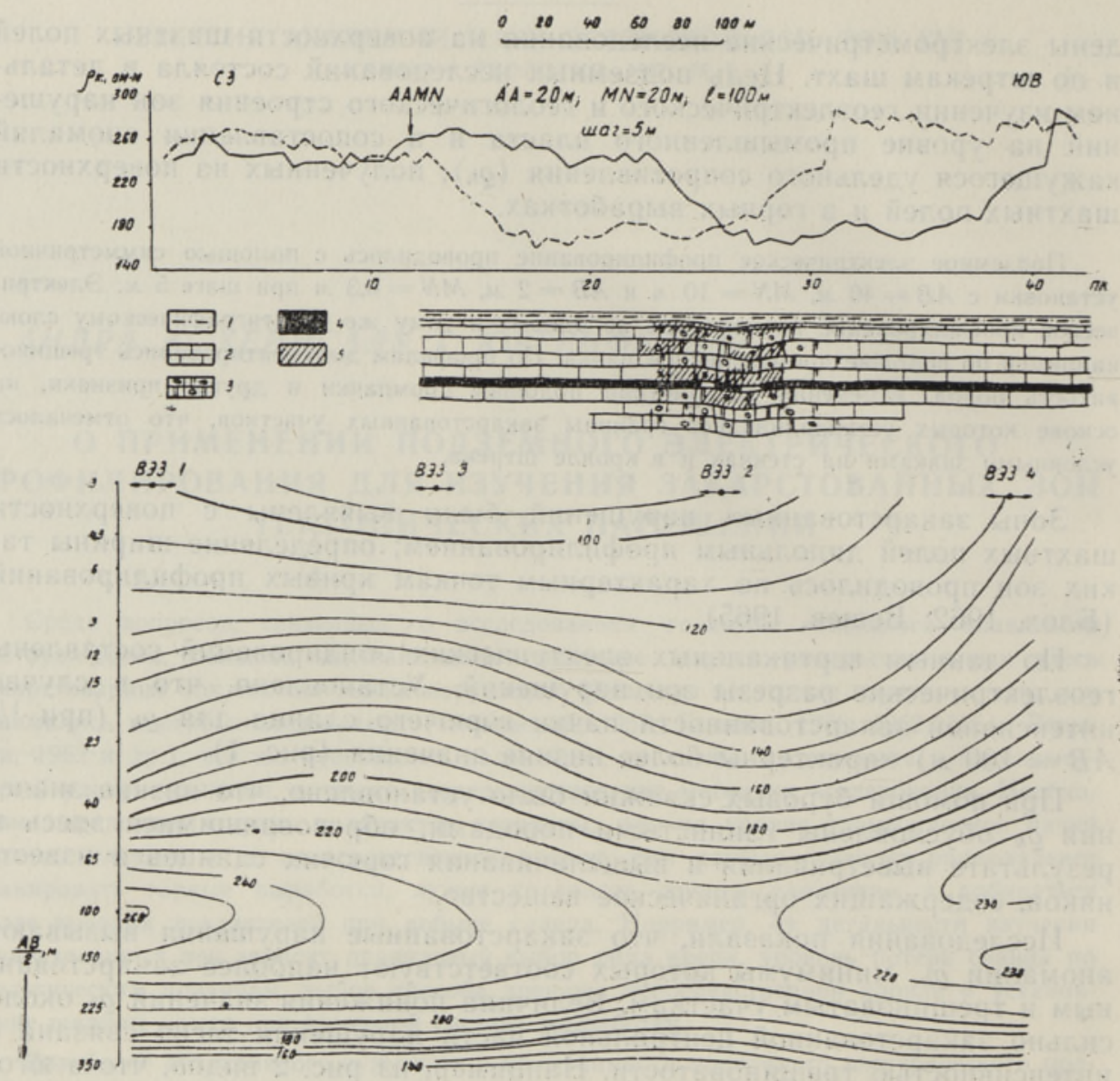

Рис. 1. Геоэлектрический разрез закарстованной зоны нарушения в сопоставлении с кривой дипольного электрического профилирования и геологическим разрезом:

1 - суглинок; 2 - известняк; 3 - кавернозный и трещиноватый доломит или доломитизированный известняк; 4 - горючий сланец; 5 - сильно закарстованные участки в нарушении.

простиранию предполагаемой зоны нарушения и выполняется дипольное электрическое профилирование в двух плоскостях - на поверхности земли и в горных выработках. Соответствующая методика разработана научным сотрудником ИГ АН ЭССР Х. Андра. Она основана на том явлении, что при переходе односторонней дипольной установкой через проводящий пласт на кривой $\varrho_{k}$ образуются два минимума. Минимум, сеязанный с пересечением пласта питающим диполем, располагается на расстоянии $l$ от пласта (Блох, 1957). По предложенной методике измерительный диполь расположен в штреке и перемещается в направлении нарушения, а питающий диполь находится на поверхности земли и передвигается синхронно впереди измерительного. Когда питающий диполь находится в пределах нарушения, создаваемое им электрическое поле сосредоточивается в проводящей зоне. Оно вызывает аномалию $\varrho_{k}$ у измерительного диполя на расстоянии $l$, что равняется в этом случае расстоянию диполя от нарушения. Результаты дипольного профилирования в двух плоскостях проверялись в месте, где зона нарушения 

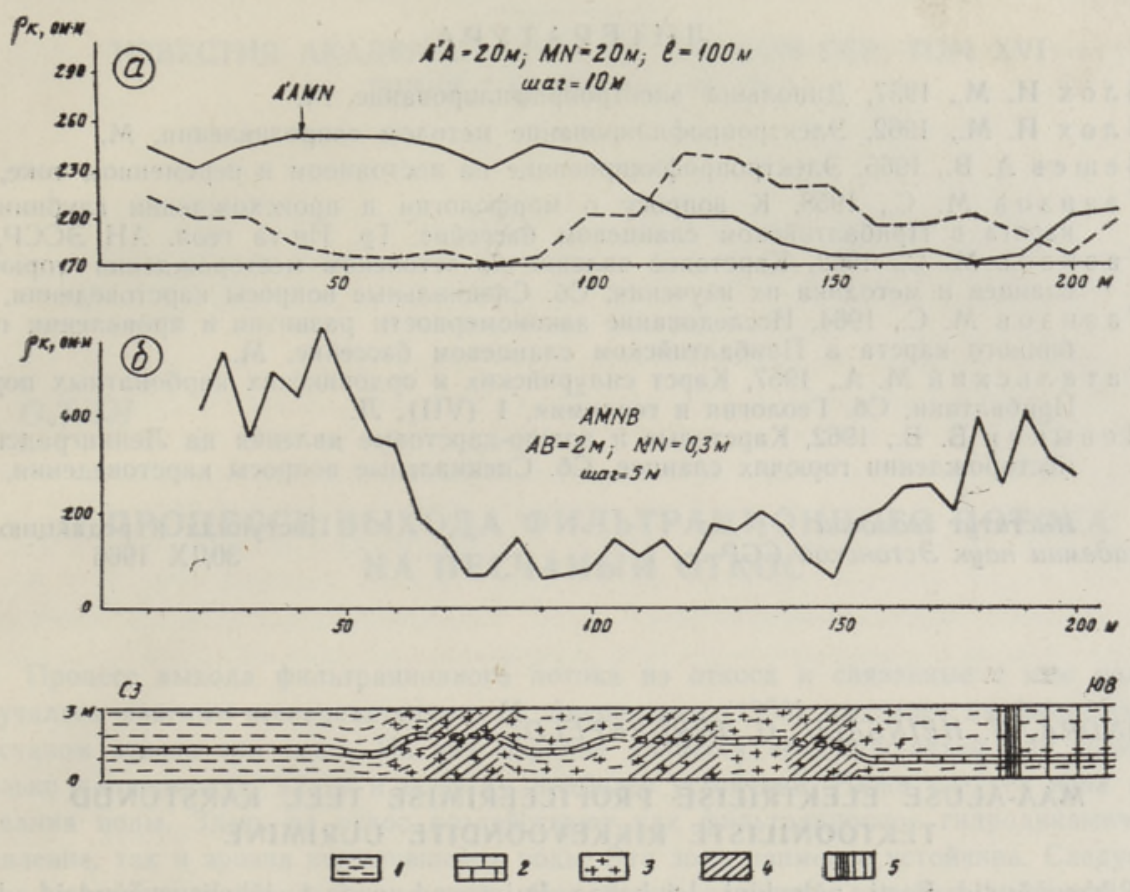

Рис. 2. Кривые электрического профилирования на поверхности земли, (a) и в горной выработке (б), сопоставленные с геологическим разрезом закарстованной зоны нарушения на уровне промышленной пачки горючих сланцев:

1 - торючий сланец; 2 - известняк (єллитаз): 3 - раздробленность; 4 - закарстованные и измененные породы; 5 - трещины.

была пройдена штреком (рис. 3). При этом использовалась установка $M N B B^{\prime}$ с $M N=20 \mu$ и $B B^{\prime}=40 \mu$ при $l=80 \mu$.

Расстояние от первого минимума $m_{1}$ до края нарушения равно $80 \mathrm{M}$, что близко к фактическому. Передвижение динолей при электрическом профилировании с диполями на двух плоскостях проводилось синхронно через определенные промежутки времени $(2,5$ мин), сигналы передавались с помощью генераторной установки путем включения и выключения тока, что регистрировалось соответствующими колебаниями стрелки измерителя. Для надежной связи можно использовать также телефон.

Рис. 3. Схема расположения диполей по отношению к зоне нарушения и соответствующая кривая электрического профилирования:

$m_{1}$ и. $m_{2}$ - характерные минимумы; $h$ - ширина зоны нарушения; $l$ расстояние между центрами диполеї.

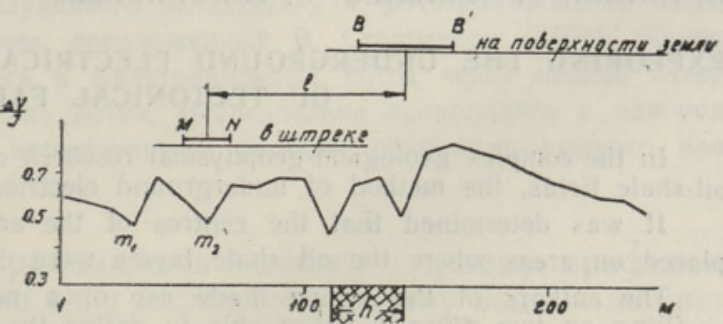

Предложенная методика может дать данные о строении зон тектонических нарушений, необходимые для ведения горных работ в случае, когда забой штрека находится на расстоянии нескольких сотен метроз от аномальной зоны. Необходимо отметить, что подземные электроразведочные работы проводились при залегании промышленной пачки торючих сланцев на глубине $20-40$ м. 


\section{ЛИТЕРАТ У РА}

1. Блох И. М., 1957, Дипольное электропрофилирование, М.

2. Блох И. М., 1962, Электропрофилирование методом сопротивления, М.

3. В еш е в А. В., 1965, Электропрофилирование на постоянном и переменном токе, Л.

4. Газизов М. С., 1958, К вопросу о морфологии и происхождении глубинного карста в Прибалтийском сланцевом бассейне, Тр. Ин-та геол. АН ЭССР, 2.

5. Г а зи зов М. С., 1962, Карстовое явление на эстонском месторождении горючих сланцев и методика их изучения, Сб. Специальные вопросы карстоведения, М.

6. Га зи зо в М. С., 1964, Исследование закономерности развития и проявления глубинного карста в Прибалтийском сланцевом бассейне, М.

7. Га т а льски й М. А., 1957, Карст силурнйских и ордовикских карбонатных пород Прибалтики, Сб. Геология и геохимия, 1 (VII), Л.

8. Л е в ык и н В. В., 1962, Карстовые и ложно-карстовые явления на Ленинградском месторождении горючих сланцев, Сб. Специальные вопросы карстоведения, $\mathbf{M}$.

Институт геологии

Академии наук Эстонской ССР
Поступила в редакцию 30/IX 1966

H. ANDRA, O. HEINSALU, G. JURGENFELDT

\section{MAA-ALUSE ELEKTRILISE PROFILEERIMISE TEEL KARSTUNUD TEKTOONILISTE RIKKEVOOONDITE UURIMINE}

Rikkevööndid Eesti põlevkivi leiukohas kujutavad endast lōhelisusvööndeid, kus karst esineb väikeste, sageli liivakassavise materjaliga täidetud ōonsustena ja kavernoossuse näol. Rikkevööndites kohtab veel omapärast karsti savikate kihtide ja savi näol, mis on moodustunud orgaanilist ainet sisaldavate kihtide asemel.

Rikkevööndite komplekssel geoloogilis-geofüüsikalisel uurimisel rakenđati maa-alust elektrilist profileerimist. Mōõdistamine toimus strekkides, mis läbisid rikkevööndeid. Uurimised näitasid, et karstunud rikkevöönd kutsub esile $\varrho_{k}$ anomaalia, mille miinimumid viitavad tugevasti karstunud ja lōhelistele kohtadele vööndis. Maapinnal saadud dipoolse profileerimise «maagirist» ja maa-alusel sümmeetrilisel profileerimisel: saadud anomaalia keskkoht tähistavad rikkevööndi keskosa tootsates kihtides. Järelikult avaldab kihtide karstumus ja löhelisus pōlevkivi tootsas osas olulist mõju elektrilise anomaalia suurusele.

Kasutades dipoolse elektrilise profileerimise viisi, kus toitedipool paikneb maapinnal ja mōôtedipool strekis, mille esi on jōudnud oletatava rikkevööndi lähedale, on vōimalik määrata rikkevööndi asukoht ja laius enne vööndi läbindamist.

\section{H. ANDRA, O. HEINSALU, G. JURGENFELDT}

\section{EXPLORING THE UNDERGROUND ELECTRICAL PROFILING FOR THE STUDY OF TECTONICAL FAILURES}

In the complex geological-geophysical research of the tectonical failures in Estonian: oil-shale fields, the method of underground electrical profiling was applied.

It was determined that the centres of the anomalies of the resistance $\varrho_{k}$ were placed on areas where the oil shale layers were damaged by tectonical failures.

The authors of the article made use of a new variant of the dipole electrical profiling on two niveaus, being able to define the character and dimensions of tectonical failures in the oil shale layers. 